\title{
Antioxidant and Antimicrobial Activities of Phenolic Components and Organic Acids from Camellia Oleifera Cake
} Jielun $\mathrm{Hu}^{1 \#}$, Duoduo Zhang ${ }^{1 \#}$, Shaoping $\mathrm{Nie}^{1}$, Mingyong $\mathrm{Xie}^{1, *}$

State Key Laboratory of Food Science and Technology, Nanchang University, 235

Nanjing East Road, Nanchang, Jiangxi Province, 330047, China; hujielun@ncu.edu.cn (J.H.); family581624@163.com (D.Z.); spnie@ncu.edu.cn (S.N.)

* Correspondence: myxie@ncu.edu.cn; Tel.: +86-791-83969009

\# These authors contribute equally to this work. 


\begin{abstract}
There is a great interest in finding antioxidants and products with antimicrobial activities from natural sources. The aim of this study was to obtain and identify the phenolic components and organic acids from Camellia oleifera cake. In addition, their antioxidant and antimicrobial activities were also investigated. The purity of phenolic components and organic acids obtained were $94.1 \pm 0.5 \% \mathrm{w} / \mathrm{w}$ and $96.0 \pm 0.3 \% \mathrm{w} / \mathrm{w}$, respectively. There are 15 phenolic components have been detected and identified by HPLC-ESI-MS. Oxalic, citric, acetic, malic, and succinic acids are found to be major organic acids. The phenolic components and organic acids both had good antioxidant capacity, evaluated by 4 antioxidant activity assays (hydroxyl radical scavenging, superoxide radical scavenging, 1,1-diphenyl-2-picryl-hydrazyl radical scavenging and lipid peroxidation inhibition). In addition, the phenolic components and organic acids exhibited significant inhibitory activity against bacteria Staphylococcus aureus, Escherichia coli, Bacillus subtilis, and fungi Mucor racemosus, Aspergillus oryzae, Rhizopus stolonifer. The phenolic components and organic acids from C. oleifera cake both showed good antioxidant capacity and exhibited antimicrobial activities. These results may be useful for the future use of phenolic components and organic acids from C. oleifera cake.
\end{abstract}

Keywords: Camellia oleifera cake; phenolic component; organic acid; antioxidant capacity; antimicrobial activity 


\section{Introduction}

Currently, more and more natural products have been found to have many benefits for the human body $[1,2]$ and there is a great interest in finding antioxidants from natural sources to prevent oxidative stress and minimize oxidative damage to living cells [3]. Oxidative damage is involved in the pathogenesis of various diseases such as atherosclerosis, cancer, diabetes mellitus and reperfusion disorder [4] Antioxidants have been widely studied because of their applications in the food industry as food preservatives and in medication as treatments against diseases that are caused by oxidative stress [5]. Accordingly, considerable attention has been paid to the evaluation of the antioxidant activity of naturally occurring substances in recent years $[6,7]$. In addition, there also has been considerable interest in natural products from plants with antimicrobial activities for controlling toxin-producing microorganisms because the use of antibiotics is no longer desirable due to concerns about bacterial resistance [8]. Increased awareness of the potential problems associated with antibiotics stimulates research efforts to carry out novel approaches to the development of new antimicrobial compounds.

Polyphenols, the secondary metabolites that have an important role in reducing oxidative stress, are reported to exhibit antioxidant activities $[9,10]$ and act as reducing agents, hydrogen donors, singlet oxygen quenchers and metal chelating agents [11]. Extracts of herbs and plant materials rich in phenolics are increasingly of interest in the food industry because they retard oxidative degradation of lipids and thereby improve the quality and nutritional value of food. There are many 
examples [12]. Phenolic compounds are also reported to have antibacterial properties $[13,14]$. In addition, organic acids are widely distributed in fruits, vegetables, herbs and plants. The content of organic acids in food could influence their nutrition, antioxidant and antimicrobial properties [15].

The seeds of Camellia oleifera contain numerous valuable compounds and nutritious oils, which are frequently used in oriental countries, especially in Southeast Asia. After the oil refining process, defatted seeds are always used as a detergent or organic fertilizer with low economic value. The remainder of seeds after oil extract is called the C. oleifera cake. There are several million tons of $C$. oleifera cakes that are discarded every year in China [8]. However, the C. oleifera cake contains large amounts of active compounds. Hence, the extraction of phenolic compounds and organic acids from C. oleifera cake will be valuable.

To the authors' knowledge, there are limited published reports on phenolic components of $C$. oleifera cake and their activities. Similarly, few researches have been done to understand the organic acid compositions of $C$. oleifera cake. Due to the lack of such information, the phenolic components and organic acids of $C$. oleifera cake along with their antioxidant and antimicrobial potentials were investigated.

\section{Experimental}

\subsection{Materials and reagents}

The seeds of $C$. oleifera were collected in Yichun County and the cakes were 
made after expression in Meiling County both from the Jiangxi Province in China. The dried cakes were battered and crushed to small pieces by a pulverizer (GC-ZN-08, Xihua Corp. Beijing, China), and then grounded by a grinder (YD-313, Youji Corp. Shanghai, China) to fine powders. The powders were then packed in a polyethylene (PE) pail and stored at room temperature $\left(15 \pm 3{ }^{\circ} \mathrm{C}\right)$ before use.

Staphylococcus aureus (1.128), Escherichia coli (1.1369), Bacillus subtilis (1.1630), fungi Mucor racemosus (3.3446), Aspergillus oryzae (3.5232), and Rhizopus stolonifer (3.4110), which were used for antimicrobial sensitivity test, were obtained from Institute of Microbiology Chinese Academy of Sciences. All the reagents used were of analytical grade and obtained from Shanghai Chemicals and Reagents Co. (Shanghai, China).

2.2. Preparation of phenolic components and organic acids

The powders of $C$. oleifera cake $(500 \mathrm{~g})$ were defatted with petroleum ether in a round-bottom flask for $3 \mathrm{~h}$. After that, the organic solvent was volatilized using a rotary evaporator (RE-52A, Yarong Bio-instrument Co., Shanghai, China), and the defatted powders were obtained.

2.2.1. Extraction and purification of phenolic component

Extraction and purification procedure of phenolic components was performed as follow: the defatted powders were extracted with $500 \mathrm{~mL} \mathrm{~L}^{-1}$ methanol [matters to solvent ratio $\left.\left(\mathrm{g} \mathrm{mL}^{-1}\right)=1: 15\right]$ in a $50{ }^{\circ} \mathrm{C}$ water bath for $2 \mathrm{~h}$. The mixtures were filtered using Whatman NO.1 filter paper. The filtrates were then concentrated by a rotary evaporator at $55{ }^{\circ} \mathrm{C}$. The concentrated filtrates were passed through AB-8 
macro-reticular resin column (80 x $20 \mathrm{~mm}$, Sigma-Aldrich, Shanghai, China) and eluted with $850,700,500$, and $300 \mathrm{~mL} \mathrm{~L}^{-1}$ ethanol, successively according to the method of Singleton \& Rossi (1965) [16]. The $300 \mathrm{~mL} \mathrm{~L}^{-1}$ ethanol eluate, which was found to contain the primary phenolic components, was considered as the phenolic component-rich fraction. This fraction was then evaporated to dryness by a rotary evaporator at $55{ }^{\circ} \mathrm{C}$. A minimum volume of distilled water was added to this fraction and the resulting solution was freeze-dried in a Freezone 12Plus lyophilizer (Labconco, USA). The procedure above was repeated several times to obtain sufficient sample.

\subsubsection{Extraction and purification of organic acids}

The defatted powders were extracted with deionized water [matters to solvent ratio $\left.\left(\mathrm{g} \mathrm{mL}^{-1}\right)=1: 10\right]$ in a $70{ }^{\circ} \mathrm{C}$ water bath for $2 \mathrm{~h}$. After that, the mixtures were filtered using Whatman NO.1 filter paper. The filtrates were evaporated by a rotary evaporator at $55{ }^{\circ} \mathrm{C}$. Then, the concentrated filtrates were passed through HPD100 macro-reticular resin column (80 x $20 \mathrm{~mm}$, Sigma-Aldrich, Shanghai, China) and eluted with distilled water and $950 \mathrm{~mL} \mathrm{~L}^{-1}$ ethanol in $\mathrm{H}_{2} \mathrm{O}$, successively. The $\mathrm{mL} \mathrm{L}^{-1}$ ethanol eluate was evaporated to dryness by a rotary evaporator at $55{ }^{\circ} \mathrm{C}$. A minimum volume of distilled water was added to this dried eluate, and then the resulting solution was freeze-dried in the Freezone 12Plus lyophilizer. The procedure above was repeated several times to obtain sufficient sample.

The obtained phenolic components and organic acids were then re-dissolved in distilled water to measure their total phenolic content, total organic acids content, 
antioxidant capacity, and antimicrobial activities.

\subsection{Phenolic determination}

\subsubsection{Total phenolic content}

Total phenolic content was analyzed using the Folin-Ciocalteu reagent according to the method described by Singleton \& Rossi (1965) [16] with some modifications. $0.2 \mathrm{~mL}$ of the sample $\left(1 \mathrm{~g} \mathrm{~L}^{-1}\right.$ dissolved in distilled water $)$ were added to a conical flask and mixed with $1 \mathrm{~mL}$ of Folin-Ciocalteu reagent and $46 \mathrm{~mL}$ of distilled water. The mixture was allowed to react for $3 \mathrm{~min}$, and $3 \mathrm{~mL}$ of aqueous solution of $\mathrm{Na}_{2} \mathrm{CO}_{3}\left(75 \mathrm{~g} \mathrm{~L}^{-1}\right)$ was added. Then the mixture was shaken vigorously. At the end of incubation for $2 \mathrm{~h}$ with intermittent shaking at room temperature, the absorbance of each mixture was measured at $760 \mathrm{~nm}$ on a TU-1900 spectrophotometer (PGeneral). The same procedure was also applied to the standard solutions of gallic acid. Total phenolic content was expressed as micrograms of gallic acid equivalents per kilogram of dry sample. The total phenolic content determination was repeated three times.

\subsubsection{Identification of phenolic compounds}

The phenolic compounds were analyzed using an Agilent 1200 HPLC-MS system containing of a surveyor auto-sampling system, interfaced to a 6430 ion-trap mass spectrometer via an electrospray ion source. HPLC was carried out on the liquid chromatograph system, equipped with a quaternary pump, a column temperature controller, and a photodiode array (PDA) detector. The analytical column temperature was kept at $35{ }^{\circ} \mathrm{C}$. The sample was separated with a RP-C18 column (4.6 mm x 250 
$\mathrm{mm}, 5 \mu \mathrm{m}$ ) using $10 \mathrm{~mL} \mathrm{~L}^{-1}$ acetic acid in water (eluent A) and $5 \mathrm{~mL} \mathrm{~L}^{-1}$ acetic acid in water and acetonitrile $(50: 50, \mathrm{v} / \mathrm{v}$; eluent $\mathrm{B})$ under gradient conditions [from 10 to $25 \% \mathrm{~B}(15 \mathrm{~min}), 25$ to $35 \% \mathrm{~B}(15 \mathrm{~min}), 35$ to $40 \% \mathrm{~B}(5 \mathrm{~min}), 40$ to $50 \% \mathrm{~B}(10 \mathrm{~min})$, 50 to $100 \% \mathrm{~B}(25 \mathrm{~min}), 100$ to $10 \% \mathrm{~B}(10 \mathrm{~min})$ ]. The mobile phase was at a flow rate of $0.3 \mathrm{~mL} \mathrm{~min}$ mithin $^{-1}$ win and the detector was employed to set at a wavelength of $280 \mathrm{~nm}$. The injection volume was $20 \mu \mathrm{L}$. Peaks were assigned by their retention time. Source settings used for the ionization of phenolic compounds were: nebulizer gas pressure of $45.00 \mathrm{psi}$; dry gas flow rate of $11.00 \mathrm{~L} \mathrm{~min}^{-1}$; electrospray voltage of the ion source of $3000 \mathrm{~V}$; capillary temperature of $350{ }^{\circ} \mathrm{C}$; fragmentor of $120.0 \mathrm{~V}$. Nitrogen $(>99.99 \%)$ and $\mathrm{He}(>99.99 \%)$ were used as sheath and damping gas, respectively.

\subsection{Determination of organic acids}

Analysis was performed on a Waters liquid chromatograph system (UK6 injector and 515 HPLC pump, Waters, Milford, MA, USA), equipped with a Waters C18 column (4.6 mm x 250 mm, $5 \mu \mathrm{m}$, Waters, Milford, MA, USA), a guard column (10 x 4 mm, Waters, Milford, MA, USA), and a Waters 2996 PDA detector connected to a Waters software. A constant elution system consisted of phosphate buffer solution $\left(20 \mathrm{mmol} \mathrm{L}^{-1} \mathrm{KH}_{2} \mathrm{PO}\right.$, $\left.\mathrm{pH}=2.7\right)$ (A) and methanol (B). The separation was achieved using the following program: $0-30 \mathrm{~min}, 5 \% \mathrm{~B}$. The flow rate was $0.5 \mathrm{~mL} \mathrm{~min}^{-1}$ and the system was operated at room temperature when the sample solution $(10 \mu \mathrm{L})$ was injected in each run. The PDA detector was set at a wavelength of $214 \mathrm{~nm}$. 


\subsection{Antioxidant activity assays}

\subsubsection{Hydroxyl radical-scavenging activity}

The hydroxyl radical scavenging ability was measured using a modified method of Halliwell et al [17]. A reaction mixture was prepared by adding $0.1 \mathrm{~mL}$ EDTA (1 $\mathrm{mM}), 0.01 \mathrm{~mL}$ of $\mathrm{FeCl}_{3}(10 \mathrm{mM}), 0.1 \mathrm{~mL}$ of $\mathrm{H}_{2} \mathrm{O}_{2}(10 \mathrm{mM}), 0.36 \mathrm{~mL}$ of deoxyribose $(10 \mathrm{mM}), 1.0 \mathrm{ml}$ of samples $\left(0.1-10 \mathrm{~g} \mathrm{~L}^{-1}\right)$ dissolved in distilled water, $0.33 \mathrm{~mL}$ of phosphate buffer $(50 \mathrm{mM}, \mathrm{pH} 7.4)$ and $0.1 \mathrm{~mL}$ of ascorbic acid $(1 \mathrm{mM})$ in sequence. The mixture was then incubated at $37^{\circ} \mathrm{C}$ for $1 \mathrm{~h} .1 .0 \mathrm{~mL}$ of the incubated mixture was mixed with $1.0 \mathrm{~mL}$ of $100 \mathrm{~mL} \mathrm{~L}^{-1}$ trichloroacetic acid and $1.0 \mathrm{~mL}$ of $5 \mathrm{~mL} \mathrm{~L}^{-1}$ thiobarbituric acid (in $25 \mathrm{mM} \mathrm{NaOH}$ containing $250 \mu \mathrm{L} \mathrm{L}^{-1}$ butylated hydroxyl anisole) to develop the pink chromogen measured at $532 \mathrm{~nm}$. The hydroxyl radical-scavenging activity of the samples was reported as the percentage of inhibition of deoxyribose degradation and was calculated according to the following equation:

$\%$ inhibition $=\left(A_{0}-A \mathrm{t}\right) / A_{0} \times 100$

where $A_{0}$ was the absorbance of the control (blank, without samples) and $A$ t was the absorbance in the presence of the samples. All of the tests were carried out in triplicate and $\mathrm{IC}_{50}$ values were expressed as means \pm standard deviation (SD). Ascorbic acid was used as a positive control.

\subsubsection{Superoxide radical-scavenging activity}

This activity was measured using nitro blue tetrazolium (NBT) reagent as described by Sabu \& Kuttan [18]. The method is based on generation of superoxide 
radical $\mathrm{O}_{2}^{-}$by auto-oxidation of hydroxylamine hydrochloride in the presence of NBT, which gets reduced to nitrite. Nitrite in the presence of EDTA gives a color that was measured at $560 \mathrm{~nm}$. Test solutions of sample $\left(0.1-10 \mathrm{~g} \mathrm{~L}^{-1}\right)$ were taken in a test tube. To this, reaction mixture consisting of $1 \mathrm{~mL}$ of $(50 \mathrm{mM})$ sodium carbonate, $0.4 \mathrm{~mL}$ of $(24 \mathrm{mM}) \mathrm{NBT}$ and $0.2 \mathrm{~mL}$ of $0.1 \mathrm{mM}$ EDTA solutions were added to the test tube and immediate reading was taken at $560 \mathrm{~nm} .0 .4 \mathrm{~mL}$ of $(1 \mathrm{mM})$ of hydroxylamine hydrochloride was added to initiate the reaction. The reaction mixture was then incubated at $25^{\circ} \mathrm{C}$ for $15 \mathrm{~min}$ and the reduction of NBT was measured at $560 \mathrm{~nm}$. Decreased absorbance of the reaction mixture indicates increased superoxide anion scavenging activity. All the samples were treated in the similar manner, absorbance was recorded and the percentage of inhibition was calculated according to the following equation:

$\%$ inhibition $=\left(A_{0}-A \mathrm{t}\right) / A_{0} \times 100$

where $A_{0}$ was the absorbance of the control (blank, without samples) and $A$ t was the absorbance in the presence of the samples. All the tests were performed in triplicate and $\mathrm{IC}_{50}$ values were obtained. Ascorbic acid was used as a positive control.

2.5.3. 1,1-diphenyl-2-picryl-hydrazyl (DPPH) radical scavenging activity

DPPH radical scavenging activity of samples was measured according to our published method [19]. The $0.2 \mathrm{mM}$ solution of DPPH in $950 \mathrm{~mL} \mathrm{~L}^{-1}$ ethanol was prepared daily before UV measurements were taken. One milliliter of the samples of different quantities $(0.1-10 \mathrm{mg})$ in water was thoroughly mixed with $2 \mathrm{~mL}$ of freshly prepared DPPH and $2 \mathrm{~mL}$ of $950 \mathrm{~mL} \mathrm{~L}^{-1}$ ethanol. The mixture was shaken vigorously 
and left to stand for $30 \mathrm{~min}$ in the dark. The absorbance of the supernatant obtained after centrifugation was then measured at $517 \mathrm{~nm}$.

The DPPH radical scavenging ability was calculated using the following equation:

$\mathrm{I} \%=\left[1-\left(A_{i}-A_{j}\right) / A_{c}\right] \times 100 \%$

where $A_{c}$ is the absorbance of DPPH solution without sample $(2 \mathrm{~mL}$ DPPH $+3 \mathrm{~mL}$ of $950 \mathrm{~mL} \mathrm{~L}^{-1}$ ethanol); $A_{i}$ is the absorbance of the test sample mixed with DPPH solution (1 mL sample $+2 \mathrm{~mL} \mathrm{DPPH}+2 \mathrm{~mL}$ of $950 \mathrm{~mL} \mathrm{~L}^{-1}$ ethanol) and $A_{j}$ is the absorbance of the sample without DPPH solution $(1 \mathrm{~mL}$ sample $+4 \mathrm{~mL}$ of $950 \mathrm{~mL}$ $\mathrm{L}^{-1}$ ethanol). All the tests were performed in triplicate and $\mathrm{IC}_{50}$ values were obtained. Ascorbic acid was used as a positive control.

\subsubsection{Inhibition of lipid peroxidation}

This test was conducted using the method of Zhang et al [20] with some modifications. Briefly, an equal volume of egg yolk was added to $0.1 \mathrm{~mol} \mathrm{~L}^{-1}$ phosphate buffered saline (PBS, pH 7.45). The mixture was stirred magnetically for $10 \mathrm{~min}$ and then diluted with 24 volumes of PBS. The yolk homogenate $(1 \mathrm{~mL})$, samples $\left(0.5 \mathrm{~mL}, 0.1-10 \mathrm{~g} \mathrm{~L}^{-1}\right)$, PBS $(1 \mathrm{~mL})$ and $25 \mathrm{mmol} \mathrm{L}^{-1} \mathrm{FeSO}_{4}(1 \mathrm{~mL})$ were mixed in a tube and shaken at $37^{\circ} \mathrm{C}$ for $15 \mathrm{~min}$. The reaction was stopped by the addition of trichloroacetic acid and the mixture was centrifuged. Then $1 \mathrm{~mL}$ of $8 \mathrm{~g}$ $\mathrm{L}^{-1}$ thiobarbituric acid solution was added to $3 \mathrm{~mL}$ of the supernatant. This solution was heated at $10{ }^{\circ} \mathrm{C}$ for $10 \mathrm{~min}$, after which its absorbance at $532 \mathrm{~nm}$ was measured. The ability to inhibit lipid peroxidation was calculated as follows: 
$\%$ inhibition $=\left[\left(B_{0}-B\right) / B_{0}\right] \times 100$

where $B_{0}$ is the absorbance of the control and $B$ is the absorbance in the presence of samples. All the tests were performed in triplicate and $\mathrm{IC}_{50}$ values were obtained. Ascorbic acid was used as a positive control.

\subsection{Antimicrobial activity assay}

The activities of different samples were tested against bacteria Staphylococcus aureus, Escherichia coli, Bacillus subtilis, and fungi Mucor racemosus, Aspergillus oryzae, Rhizopus stolonifera. The bacteria and fungi were grown and maintained on nutrient agar medium slants and potato medium slants respectively when they were obtained from the Institute of Microbiology Chinese Academy of Sciences. Before inoculation, the liquid nutrient medium for bacteria and potato mediums for fungi were autoclaved at $121{ }^{\circ} \mathrm{C}$ in vertical heating pressure stream sterilizer (LDZX-50KB, Shenan Medical Instrument Works Co., Shanghai, China) for 20 min. After that, a loop of each microorganism was inoculated into cool liquid medium. They were then stored under aerobic conditions. The three bacteria were cultivated $24 \mathrm{~h}$ at $37^{\circ} \mathrm{C}$, while the three fungi were cultivated $48 \mathrm{~h}$ at $30^{\circ} \mathrm{C}$ which was further adjusted to obtain a suitable turbidity for further use [21]. After cultivation, average counts of bacteria Staphylococcus aureus, Escherichia coli and Bacillus subtilis were $3.5 \times 10^{6}, 8.6 \times 10^{5}, 5.4 \times 10^{6}$ colony forming units $(\mathrm{cfu}) \mathrm{mL}^{-1}$, and for fungi Mucor racemosus, Aspergillus oryzae, and Rhizopus stolonifer were 1.5 x 106, 7.4 x $10^{6}$, and $2.9 \times 10^{6}\left(\mathrm{cfu} \mathrm{mL}^{-1}\right)$, respectively. $\mathrm{Cfu} \mathrm{mL}^{-1}$ density of cultures was confirmed after distribution into assay plates by the following procedure. All 
bacterial and fungi stock cultures were serially diluted 10-fold in a series of tubes, and plated by inoculating $100 \mu \mathrm{L}$ onto medium plates which were incubated, and then colonies were counted to calculate density of the bacterial and fungi stock cultures.

\subsubsection{Determination of inhibitory effect}

The inhibition zone method was firstly employed to determine the antimicrobial activity of the samples [22]. Twenty milliliters of medium were poured into each Petri dish. After the medium had solidified, $100 \mu \mathrm{L}$ of suspension of the test microorganisms were smeared onto it. The wells were made, and the samples (100 or $\left.200 \mathrm{mg} \mathrm{L}^{-1}\right)$ were added to these wells $(20 \mu \mathrm{L})$ and the same volume $(20 \mu \mathrm{L})$ of gentamicin $\left(1 \mathrm{~g} \mathrm{~L}^{-1}\right)$ was used as a positive control. Deionized water was used as negative control. The inoculated plates were incubated and the diameter $(\mathrm{mm})$ of the inhibition zone expressed as an average of the maximum diameter in three different directions was measured after the bacteria were cultivated $24 \mathrm{~h}$ at $37{ }^{\circ} \mathrm{C}$ and the fungi were cultivated $48 \mathrm{~h}$ at $30^{\circ} \mathrm{C}$.

\subsubsection{Determination of minimum inhibitory concentration}

Minimum inhibitory concentration (MIC) was determined by liquid medium dilution method [23]. Two-fold serial dilutions of the samples with appropriate antibiotic control were prepared in liquid nutrient medium for bacteria and potato mediums for fungi [24]. For liquid medium dilution test, $100 \mu \mathrm{L}$ of stock cultures of bacteria or fungi were added to each tube (containing two-fold serial dilutions of sample at a final concentration of $7.8-4000 \mathrm{mg} \mathrm{L}^{-1}$ for bacteria and fungi) and 
incubated either at $37^{\circ} \mathrm{C}$ for bacteria or at $30^{\circ} \mathrm{C}$ for fungi for $24 \mathrm{~h}$ or $48 \mathrm{~h}$. After the cultivation period, the turbidity was taken as the indication of growth and the lowest concentration which remained clear after microscopic evaluation was thus taken as the MIC, which was recorded as the mean concentration of triplicates.

\subsection{Statistical analysis}

All the experiments were done in triplicate. Statistical analysis was carried out using SPSS (version 16.0, Chicago, United States). The results were expressed as mean \pm standard deviations and compared using the Tukey test at 5\% confidence level.

\section{Results and discussion}

3.1. Phenolic components and organic acids

Phenolics are aromatic secondary plant metabolites, and are widely spread throughout the plant kingdom [25]. The purity of phenolic components obtained from C. oleifera cake is $94.1 \pm 0.5 \% \mathrm{w} / \mathrm{w}$. Figure 1 showed the HPLC chromatogram of the phenolic components. Under the LC-MS, the MS spectra of phenolic components from $C$. oleifera cake were acquired in the positive ion mode and Table 1 presented their most possible identification. Among the phenolics, there are 15 phenolic components have been detected (Figure 1, Table 1). Identification were aided by comparison with reference standards where available and by correlation with previous literature reports. The detected phenolic components are pelargonidin-diglucoside, gallotannin, ellagitannin, cyanidin-glucoside, pelargonidin-glucoside, catechin, 
p-coumaroyl-glucoside, $\quad$-coumaroyl-ester, $\quad p$-coumaroyl-glucoside, quercetin-rutinoside, ellagic acid, quercetin-glucoside, quercetin-glucuronide, methyl-ellagic acid-pentose, and kaempferol-glucuronide.

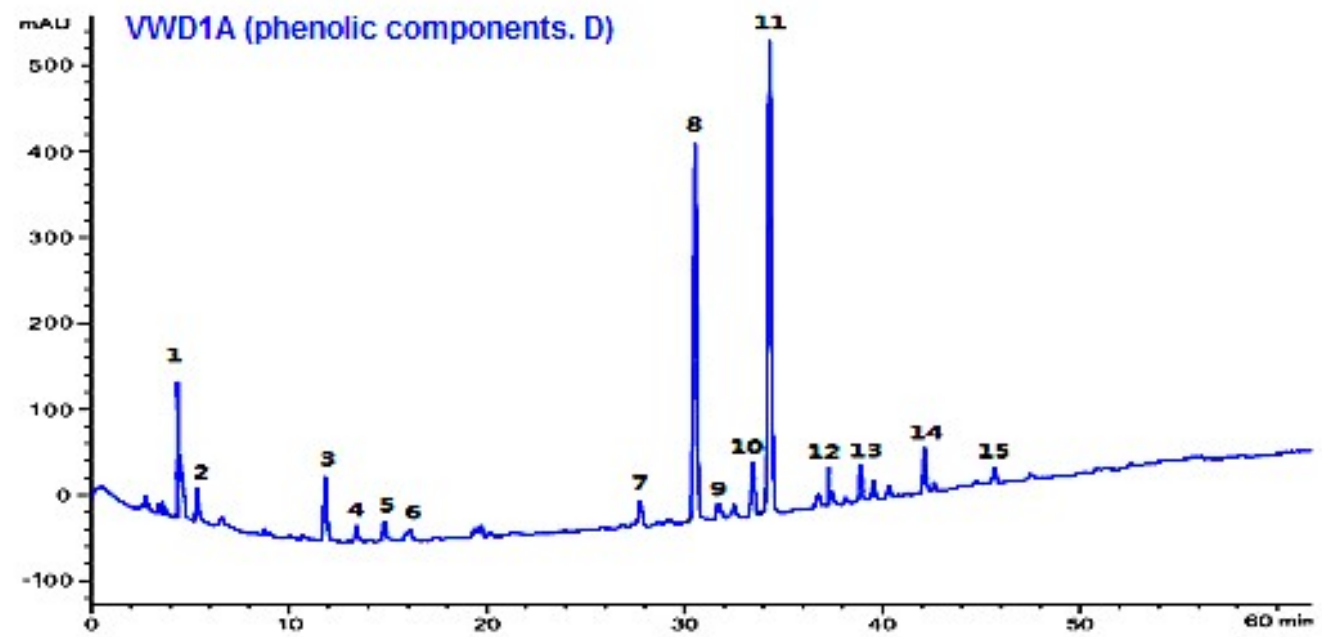

Figure 1. The HPLC chromatogram of the phenolic components.

Table 1. Identification of phenolic compounds from $C$. oleifera cake using their HPLC-DAD, LC-MS and LC-MS ${ }^{\mathrm{n}}$ data.

\begin{tabular}{clll}
\hline Peak $^{\mathrm{a}}$ & $\mathrm{t}_{\mathrm{R}}(\min )$ & $\mathrm{Mw}$ & \multicolumn{1}{c}{ Tentative ID } \\
\hline 1 & 4.25 & 594 & Plg-diglucoside \\
2 & 5.32 & 784 & Gallotannin \\
3 & 11.89 & 640 & Ellagitannin \\
4 & 13.64 & 448 & Cyanidin-glucoside \\
5 & 14.58 & 432 & Plg-glucoside \\
6 & 16.03 & 290 & Catechin \\
7 & 27.76 & 325 & $p$-coumaroyl-glucoside \\
8 & 30.29 & 356 & $p$-coumaroyl-ester \\
9 & 31.82 & 326 & $p$-coumaroyl-glucoside \\
10 & 31.74 & 610 & Quercetin-rutinoside \\
11 & 34.20 & 302 & Ellagic acid \\
12 & 37.41 & 464 & Quercetin-glucoside \\
13 & 39.03 & 478 & Quercetin-glucuronide \\
14 & 42.10 & 448 & Methyl-ellagic acid -pentose \\
15 & 45.88 & 462 & Kaempferol-glucuronide \\
\hline
\end{tabular}


a Peak numbers refer to HPLC chromatograms in Figure1.

Organic acids are important for their contribution to sensory attributes and nutrition value in fruits and plants [26]. The purity of organic acids obtained from $C$. oleifera cake is $96.0 \pm 0.3 \% \mathrm{w} / \mathrm{w}$. Oxalic, citric, acetic, malic and succinic acids are found to be major organic acids in the C. oleifera cake (Figure 2).

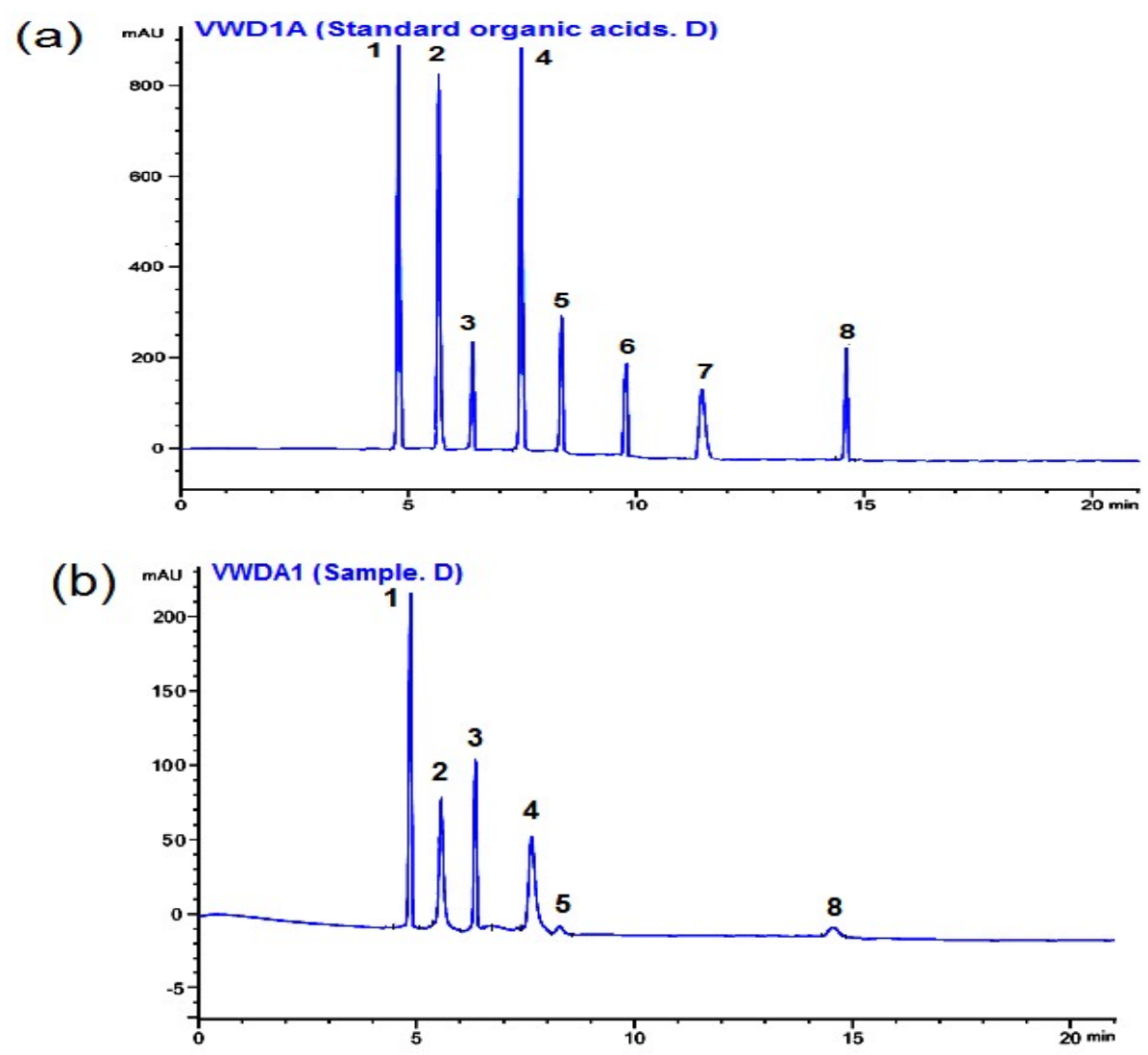

Figure 2. Liquid chromatograms of standards and samples. (a)standard organic acids;

(b)sample.

\subsection{Antioxidant activities}

The importance of antioxidant constituents from plant materials is raising interest among scientists, food manufacturers, and consumers, as the trend of the future is moving towards functional food with specific beneficial effects [27]. The 
phenolic compounds have been reported to have multiple biological effects, including antioxidant activity [28] reported that phenolic compounds in plants possess antioxidant activity, and may help protect cells against the oxidative damage caused by free radicals. The function of organic acids, in the reactive oxygen species scavenging, has also been demonstrated by other authors [29]. In this study, antioxidant activity of phenolic compounds and organic acids were evaluated using four different assays. The $\mathrm{IC}_{50}$ values of different samples were summarized in Table 2.

As shown in Table 2, phenolic components $\left(\mathrm{IC}_{50}=184 \pm 2 \mathrm{mg} \mathrm{L}^{-1}\right)$ had more scavenging power for hydroxyl radical than organic acids $\left(\mathrm{IC}_{50}=594 \pm 3 \mathrm{mg} \mathrm{L}^{-1}\right)$ and ascorbic acid $\left(\mathrm{IC}_{50}=220 \pm 3 \mathrm{mg} \mathrm{L}^{-1}, p<0.05\right)$.

Table 2. Half-inhibition ( $\left.\mathrm{IC}_{50}\right)$ values of antioxidant activities of phenolic components and organic acids measured using hydroxyl radical-scavenging, superoxide radical-scavenging, DPPH radical scavenging and inhibition of lipid peroxidation assays.

\begin{tabular}{lcccc}
\hline & \multicolumn{4}{c}{$\mathrm{IC}_{50}\left(\mathrm{mg} \mathrm{L}^{-1}\right)^{\mathrm{a}}$} \\
\cline { 2 - 5 } & Hydroxyl & Superoxide & DPPH radical & Lipid peroxidation \\
& radical-scavenging & radical-scavenging & scavenging & inhibition \\
\hline Phenolic components & $184 \pm 2 \mathrm{a}^{\mathrm{b}}$ & $221 \pm 2 \mathrm{a}$ & $103 \pm 8 \mathrm{a}$ & $203 \pm 8 \mathrm{a}$ \\
Organic acids & $594 \pm 3 \mathrm{~b}$ & $671 \pm 3 \mathrm{~b}$ & $184 \pm 5 \mathrm{~b}$ & $376 \pm 8 \mathrm{~b}$ \\
Ascorbic acid $^{\mathrm{c}}$ & $220 \pm 3 \mathrm{c}$ & $304 \pm 5 \mathrm{c}$ & $205 \pm 3 \mathrm{c}$ & $440 \pm 3 \mathrm{c}$ \\
\hline
\end{tabular}

${ }^{a}$ The $\mathrm{IC}_{50}$ value is expressed as $\mathrm{mg} \mathrm{L}^{-1}$ and represents the concentration of sample that is required for $50 \%$ inhibition of hydroxyl radical, superoxide radical, DPPH radical, and lipid peroxidation. A lower $\mathrm{IC}_{50}$ value indicates a higher antioxidant activity. Each value in the table was obtained by calculating the average of three determinations \pm standard deviation.

${ }^{\mathrm{b}}$ Mean values in the same column with different letters are significantly different (Tukey test, $p$ $<0.05)$. 
${ }^{\mathrm{c}}$ Ascorbic acid was used as a positive control.

Superoxide anion plays an important role in the formation of reactive oxygen species such as hydrogen peroxide, hydroxyl radical, and singlet oxygen, which induces oxidative damage in lipids, protein, and DNA [31]. In this study, the $\mathrm{IC}_{50}$ value for superoxide radical scavenging ability of phenolic components $(304 \pm 5 \mathrm{mg}$ $\mathrm{L}^{-1}$, Table 2) was higher than organic acids $\left(671 \pm 3 \mathrm{mg} \mathrm{L}^{-1}\right)$ and ascorbic acid ( $\mathrm{IC}_{50}$ $\left.=304 \pm 5 \mathrm{mg} \mathrm{L}^{-1}, p<0.05\right)$.

The model of scavenging the stable DPPH radical is a widely used method of evaluating the free radical scavenging ability of natural compounds. The effect of antioxidants on DPPH radical scavenging was thought to be due to their hydrogen-donating ability [32]. The DPPH scavenging activity of the phenolic components expressed in the term of $\mathrm{IC}_{50}$ was $103 \pm 8 \mathrm{mg} \mathrm{L}^{-1}$ (Table 2), with the higher DPPH scavenging power than that of organic acids $\left(184 \pm 5 \mathrm{mg} \mathrm{L}^{-1}\right)$ and ascorbic acid $\left(205 \pm 3 \mathrm{mg} \mathrm{L}^{-1}\right)(p<0.05)$.

Lipid peroxidation (oxidative degradation of polyunsaturated fatty acid in the cell membranes) generates a number of degradation products, such as malondialdehyde (MDA), which is found to cause cell membrane destruction and cell damage, leading to liver injury, atherosclerosis, kidney damage, aging, and susceptibility to cancer [33]. The $\mathrm{IC}_{50}$ value $\left(\mathrm{mg} \mathrm{L}^{-1}\right)$ showed the lipid peroxidation inhibitory capacity of phenolic components $\left(\mathrm{IC}_{50}=203 \pm 8 \mathrm{mg} \mathrm{L}^{-1}\right)$ was stronger than organic acids $\left(\mathrm{IC}_{50}=376 \pm 8 \mathrm{mg} \mathrm{L}^{-1}\right)$ and ascorbic acid $\left(\mathrm{IC}_{50}=440 \pm 3 \mathrm{mg} \mathrm{L}^{-1}\right.$, $p<0.05)$.

There are 15 phenolic components have been detected in C. oleifera cake 
(Figure1, Table 1). It could be seen from the results above that these phenolic compounds in $C$. oleifera cake showed good antioxidant capacity for hydroxyl radical scavenging, superoxide radical scavenging, DPPH scavenging and lipid peroxidation inhibition. It was also reported that phenolic compounds have good radical-scavenging ability [34] and are also potent metal chelators and lipid peroxidation inhibitors [35], which was consistent with our results. In addition, different phenolic compounds may have various antioxidant capacities [36]. determined the inhibition of lipid oxidation of the phenolic compounds and found that catechin, quercetin and ellagic acid could have different antioxidant capacities, in a linoleic acid system. Meanwhile, the free radical-scavenging activity of them was also different. Thus, the phenolic compounds that we found in C. oleifera cake may also have different antioxidant capacities.

Other molecules, such as organic acids, are also present in a great amount in plants, fruits or vegetables. Previous studies attributed a direct action on free radicals scavenging and other antioxidant capacity to some organic acids [37]. Besides, an effective antioxidant action of organic acids is well-known as their chelating action, which could inactivate reducing cations. In this study, oxalic, citric, acetic, malic and succinic acids are found to be major organic acids in the $C$. oleifera cake (Figure 2). It was reported that citric acid and other hydroxycarboxylic acids such as tartaric, malic and isocitric acids also have antioxidant activity, for example, hydroxycarboxylic acids act as metal scavengers, and stimulate the decomposition of hydroperoxides by pathways that do not result in the formation of free radicals [38]. 
These results was consistent ours. In addition, some other works confirmed that organic acids possess the biological activity both in reducing reactive oxygen species and in enhancing phenolics bio-availability [39]. Thus, it could be supposed that the organic acids in $C$. oleifera cake might also enhance the antioxidant activity of the phenolic compounds in C. oleifera cake.

\subsection{Antimicrobial activities}

Plants can possess antimicrobial natural products to protect themselves from microbial infection and deterioration [40]. There are growing interests in using natural antimicrobial compounds, especially extracted from plants, for the preservation of foods. In addition, there are more consumers who tend to question the safety of synthetic additives and would prefer natural foodstuffs [41]. Antimicrobial activities of some spices in plant leaves, flowers, stems, roots, or fruits have been reported by scientists. The phenolic compounds and organic acids are very important antimicrobial compounds in plants [42].

Salmonella spp. is one of the major foodborne pathogens, and the widespread increase in the number of cases of salmonella infection in recent years has major social and economic consequences. Escherichia coli strains are also associated with adverse gastrointestinal incidents [43]. The inhibition zone diameters of the phenolic components and organic acids from $C$. oleifera cake are shown in Figure 3, and the MICs are shown in Table 3. As shown in Figure 3, there is significant difference in the diameter of inhibition zone for phenolic components and organic acids (100 or 200 $\mathrm{mg} \mathrm{L}^{-1}$ ) compared with deionized water (negative control, $p<0.05$ ). It was indicated 
from Figure 3 that phenolic components and organic acids (100 or $\left.200 \mathrm{mg} \mathrm{L}^{-1}\right)$ could inhibit these three bacteria, and their inhibiting capacity was sometimes better than gentamicin (positive control, $1 \mathrm{~g} \mathrm{~L}^{-1}$ ).

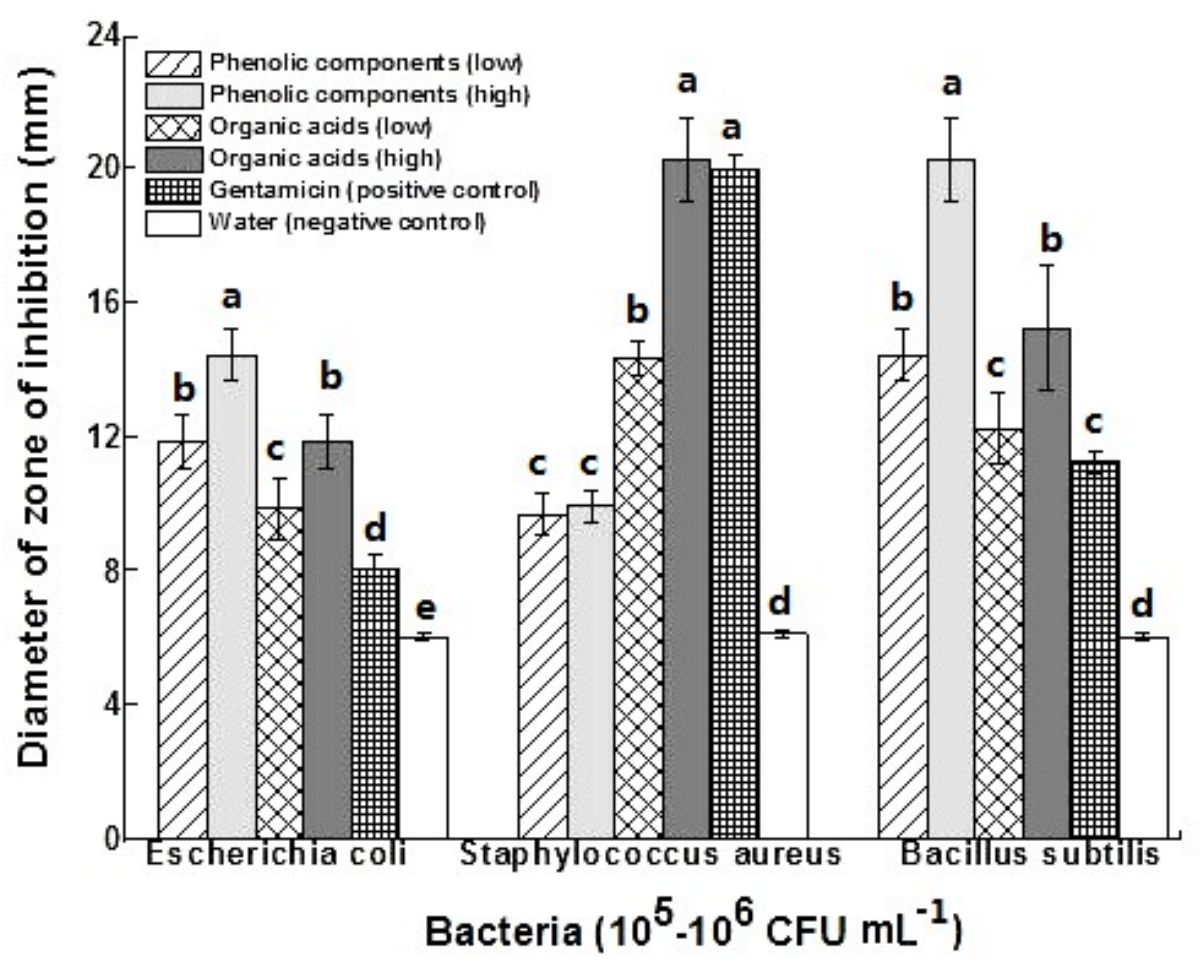

Figure 3. Diameter of zone of inhibition.

Table 3. MICs a of antimicrobial activity for phenolic components and organic acids from $C$. oleifera cake against bacteria and fungi.

\begin{tabular}{lcc}
\hline \multirow{2}{*}{ Microorganisms } & \multicolumn{2}{c}{ MIC $\left(\mathrm{mg} \mathrm{L}^{-1}\right)$} \\
\cline { 2 - 3 } & Phenolic components & Organic acids \\
\hline Escherichia coli & 125 & 250 \\
Staphylococcus aureus & 250 & 63 \\
Bacillus subtilis & 63 & 125 \\
Rhizopus stolonifer & 500 & 1000 \\
Aspergillus oryzae & 1000 & 500 \\
Mucor racemosus & 2000 & 1000 \\
\hline
\end{tabular}

${ }^{a}$ The lowest concentration which the liquid medium remained clear after microscopic evaluation was taken as the minimum inhibitory concentration (MIC). It was recorded as the mean 
concentration of triplicates.

Inhibition zones of the phenolic components and organic acids for each assay on test bacteria showed an opposite relationship with MIC (Table 3). A lower MIC indicates a stronger antimicrobial activity. As shown in Table 3, MIC was at 125, 250 and $63 \mathrm{mg} \mathrm{L}^{-1}$ for phenolic components against bacteria Escherichia coli, Staphylococcus aureus and Bacillus subtilis, while it was 250,63 and $125 \mathrm{mg} \mathrm{L}^{-1}$ for organic acids against the same bacteria. When against fungi, Rhizopus stolonifer was affected by the phenolic components and organic acids as the MICs were 500 and $1000 \mathrm{mg} \mathrm{L}{ }^{-1}$. In addition, phenolic components and organic acids could inhibit Aspergillus oryzae with MIC level of 1000 and $500 \mathrm{mg} \mathrm{L}^{-1}$. Furthermore, MIC was 2000 and $1000 \mathrm{mg} \mathrm{L}^{-1}$ for phenolic components and organic acids, respectively against fungi Mucor racemosus. These results suggested that the phenolic components and organic acids had lower inhibitory activity against fugi than bacteria tested.

It is important to find food additives and preservatives for preventing food deterioration and extending the shelf life of perishable food ingredients. Many phenolic compounds are known to possess antimicrobial properties. In this work, there are 15 phenolic components found in C. oleifera cake (Figure 1, Table 1). It was also reported that ellagitannins could be one of the main phenolic components causing the inhibition against Salmonella [35], which was also one of our detected phenolic components in $C$. oleifera cake. In addition, different bacterial species exhibit different sensitivities towards phenolics, and the variations may come from the cell surface structures between Gram-negative and Gram-positive bacteria. In particular, 
the outer membrane of Gram-negative bacteria could be a preventive barrier against hydrophobic compounds [44]. However, sometimes phenolics also showed activity against Gram-negative bacteria [35], which was consistent with our results. Helander et al. (1998) found some phenolic compounds could inhibit E. coli and Salmonella, and the inhibitory mechanism involved the disruptive action of these compounds on the outer membrane [44]. The antimicrobial activity of phenolics may also be due to the glycosides in phenolics [45]. Thus, the antimicrobial activities of the phenolic compounds from $C$. oleifera cake may also result from their glycosides.

Specific organic acids have also been advised to control microbial contamination and dissemination of foodborne pathogens in food production and processing [46]. In this study, oxalic, citric, acetic, malic and succinic acids are found to be major organic acids in the $C$. oleifera cake (Figure 2). The antibacterial mechanisms for organic acids may depend on physiological status of the organism or the physicochemical characteristics of the external environment [47]. Other toxicity mechanisms have also been proposed that organic acids may possess membrane uncoupling capacity [48]. Furthermore, undissociated acids are considered to be the active form, because they can freely diffuse through the cell membrane and enter the cytoplasm [49]. However, the toxic mechanisms of organic acids (either directly or indirectly) for foodborne pathogens have not been fully elucidated. This is in part due to complexities involved in organic acids, and factors such as chain length, side chain composition, and hydrophobicity could affect the antimicrobial activity of organic acids [50]. This could be investigated in future study. 


\section{Conclusions}

Phenolic components and organic acids were obtained and identified from $C$. oleifera cake. The phenolic components and organic acids both showed good antioxidant capacity and exhibited significant inhibitory activity against bacteria Staphylococcus aureus, Escherichia coli, Bacillus subtilis, and fungi Mucor racemosus, Aspergillus oryzae, Rhizopus stolonifer. These results could provide useful information for the future use of phenolic components and organic acids from C. oleifera cake.

Acknowledgements: This study was supported by the National Key Research and Development Program of China (2017YFC1600405), Jiangxi Provincial Major Program of Research and Development Foundation (Agriculture field, 20165ABC28004), and National Natural Science Foundation of China (31501483 and 31770861).

Author Contributions: M.X. conceived and designed the research; J.H. collected the data, performed the statistical analysis and wrote the paper; D.Z. performed paper-related typesetting work; S.N. revised the paper; and M.X. had primary responsibility for final content. All authors read and approved the final manuscript.

Conflicts of interest statement: The authors declare no competing financial interest.

\section{References}

1. Hu, J.L.; Nie, S.P.; Xie, M.Y. Antidiabetic Mechanism of Dietary Polysaccharides Based on Their Gastrointestinal Functions. J. Agr. Food. Chem. 2018, 66(19), 
4781-4984.

2. Nie, Q.X.; Hu, J.L; Gao, H; Fan, L.L; Chen. H.H; Nie, S.P. Polysaccharide from Plantago asiatica L. attenuates hyperglycemia, hyperlipidemia and affects colon microbiota in type 2 diabetic rats. Food. Hydrocolloids. doi: 10.1016/j.foodhyd.2017.12.026.

3. Finkel, T.; Holbrook, N.J. Oxidants, oxidative stress and the biology of ageing. Nature. 2000, 408, 239-247.

4. Mariappan G, S.B.; Bhuyan NR; Bharti PR; Kumar D. Evaluation of antioxidant potential of pyrazolone derivatives. Journal of Advanced Pharmaceutical Technology \& Research, 2010, 1, 260-267.

5. Masuda, T.; Inaba, Y.; Maekawa, T.; Takeda, Y.; Yamaguchi, H.; Nakamoto, K.; Kuninaga, H.; Nishizato, S.; Nonaka, A. Simple detection method of powerful antiradical compounds in the raw extract of plants and its application for the identification of antiradical plant constituents. J. Agr. Food. Chem. 2003, 51, 1831-1838.

6. Jayaprakasha, G.K.; Jaganmohan Rao, L.; Sakariah, K.K. Antioxidant activities of flavidin in different in vitro model systems. Bioorgan. Med. Chem. 2004. 12, 5141-5146.

7. Ester Hernández-Corroto; María Luisa Marina; María Concepción García. Multiple protective effect of peptides released from Olea europaea and Prunus persica seeds against oxidative damage and cancer cell proliferation. Food. Res. Int. 2018, 106, 458-467. 
8. Shen, J.; Cao, C.; Su, H.; Yang, X.; Wei, Z.; Du, L. Evidence of gastro-intestinal system as an active and toxic target of sasanqua saponins extract. Exp. Toxicol. Pathol, 2008, 60, 43-49.

9. Borges, F.; Roleira, F.; Milhazes, N.; Santana, L.; Uriarte, E. Simple coumarins and analogues in medicinal chemistry: Occurrence, synthesis and biological activity. Curr. Med. Chem. 2005, 12, 887-916.

10. Mattera, R.; Benvenuto, M.; Giganti, M.G.; Tresoldi, I.; Pluchinotta, F.R.; Bergante, S,; Tettamanti, G.; Masuelli, L.; Manzari, V.; Modesti, A.; Bei, Roberto. Effects of Polyphenols on Oxidative Stress-Mediated Injury in Cardiomyocytes. Nutrients. 2017, 9(5).

11. Hamilton, R.J.; Kalu, C.; Prisk, E.; Padley, F. B.; Pierce, H. Chemistry of free radicals in lipids. Food. Chem. 1997, 60, 193-199.

12. Difonzo, G.; Pasqualone, A.; Silletti, R.; et al. Use of olive leaf extract to reduce lipid oxidation of baked snacks. Food. Res. Int. 2018, 108, 48-56.

13. Shui, G. ; Leong, L.P. Separation and determination of organic acids and phenolic compounds in fruit juices and drinks by HPLC. J. Chromatogr. A. 2002, 977, 89-96.

14. Zhang, G.W. ; Hu, M.M. ; He, L. ; Fu, P. ; Wang, L. ; Zhou, J. Optimization of microwave-assisted enzymatic extraction of polyphenols from waste peanut shells and evaluation of its antioxidant and antibacterial activities in vitro. Food. Bioprod. Process. 2013, 91(2).

15. Poyrazoglu, E.; Gokmen, V.; Artik, N. Organic acids and phenolic compounds in 
pomegranates (Punica grganatum L.) grown in Turkey. J. Food. Compos. Anal. 2002, $14,567-575$.

16. Singleton, V.L.; Rossi, J.A. Colorimetry of total phenolics with phosphomolybdic-phosphotungstic acid reagents. Am. J. Enol. Viticult. 1965, 16, 144-158.

17. Halliwell, B.; Gutteridge, J.; Aruoma, O.I. The deoxyribose method: a simple "test-tube" assay for determination of rate constants for reactions of hydroxyl radicals. Anal. Biochem. 1987, 165, 215-219.

18. Sabu, M.; Kuttan, R. Anti-diabetic activity of medicinal plants and its relationship with their antioxidant property. J. Ethnopharmacol. 2002, 81, 155-160.

19. Chen, Y.; Xie, M.Y.; Nie, S.P.; Li, C.; Wang, Y.X. Purification, composition analysis and antioxidant activity of a polysaccharide from the fruiting bodies of Ganoderma atrum. Food. Chem. 2008, 107, 231-241.

20. Zhang, E.X.; Yu, L.J.; Zhou, Y.L.; Xiao, X. Studies on the peroxidation of polyunsaturated fatty acid from lipoprotein induced by iron and the evaluation of the anti-oxidative activity of some natural products. Sheng Wu Hua Xue Yu Sheng Wu Wu Li Xue Bao. 1996, 28, 218-222.

21. Vandepitte, J.; Engback, K.; Piot, P.; Heuck, C.C. Basic microbiology procedures in clinical bacteriology. Geneva: World Health Organization. 1991, 85.

22. Rose, N. R.; Friedman, H. Manual of clinical immunology. Washington DC: ASM. 1976.

23. Chattopadhyay, D.; Mukherjee, T.; Pal, P.; Saha, B.; Bhadra, R. Altered 
membrane permeability as the basis of bactericidal action of methdilazine. $J$. Antimicrob. Chemot. 1998, 42, 83-86.

24. Ibrahim, D.; Osman, H. Antimicrobial activity of Cassia alata from Malaysia. $J$. Ethnopharmacol, 1995, 45, 151-156.

25. Robbins, R.J. Phenolic acids in foods: An overview of analytical methodology. J. Agr. Food. Chem. 2003, 51, 2866-2887.

26. Holloway, W.D.; Argall, M.E. Jealous, W.T.; Lee, J.A.; Bradbury, J. H. Organic acid and calcium oxalate in tropical root crops. J. Agr. Food. Chem. 1989, 37, 337-341.

27. Akram, K.; Kwon, J.H. Food irradiation for mushrooms: A review. J. Korean. Orean. Soc. Appl. Bi. 2010, 53, 257-265.

28. Kirakosyan, A.; Seymour, E.; Kaufman, O.B.; Warber, S.; Bolling, S.; Chang, S.C. Antioxidant capacity of polyphenolic extracts from leaves of Crataegus laevigata and Crataegus monogyna (Hawthorn) subjected to drought and cold stress. J. Agr. Food. Chem. 2003, 51, 3973-3976.

29. Sentjurc, M.; Nemec, M.; Connor, H.D.; Abram, V. Antioxidant activity of Sempervivum tectorum and its components. J. Agr. Food. Chem. 2003, 51, 2766-2771.

30. Hochstein, P.; Atallah, A.S. The nature of oxidants and antioxidant systems in the inhibition of mutation and cancer. Mutation Research/Fundamental and Molecular Mechanisms of Mutagenesis. 1988, 202, 363-375.

31. Pietta, P.G. Flavonoids as antioxidants. J. Nat. Prod. 2000, 63, 1035-1042. 
32. Milardovic, S.; Ivekovic, D.; Grabaric, B.S. A novel amperometric method for antioxidant activity determination using DPPH free radical. Bioelectrochemistry. 2006, 68, 175-180.

33. Rice-Evans, C.; Burdon, R. Free radicals-lipid interaction and their pathological consequences. Prog. Lipid. Res. 1993, 32, 71-110.

34. Zhang, L.L.; Wang, Y.M.; Xu, M.; Chen, J.H. Comparisons of antioxidant activity and total phenolics of Camellia oleifera Abel fruit hull from different regions of China. J. Med. Plants. Res. 2010, 4, 1407-1413.

35. Puupponen-Pimiä, R.; Nohynek, L.; Meier, C.; Kaähkoönen, M.; Heinonen, M.; Hopia, A.; Oksman-Caldentey, K.M. Antimicrobial properties of phenolic compounds from berries. J. Appl. Microbiol. 2001, 90, 494-507.

36. Sanchez-Moreno, C.; Larrauri, J.A.; Saura-Calixto, F. Free radical scavenging capacity and inhibition of lipid oxidation of wines, grape juices and related polyphenolic constituents. Food. Res. Int. 1999, 32, 407-412.

37. Chang, C.; Chen, J. Study on the protective mechanism of organic acids in human umbilical vein endothelial cells. Acta Nutrimenta Sinica. 2004, 26, 280-283.

38. Pokorný, J. Natural antioxidants for food use. Trends. Food. Sci. Tec. 1991, 2, 223-227.

39. van den Berg, A.J.; Halkes, S.B.; van Hufford, H.C.; Hoekstra, M.J.; Beukelman, C.J. A novel formulation of metal ions and citric acid reduces reactive oxygen species in vitro. J. Wound. Care. 2003, 12, 413-418.

40. Cowan, M.M. Plant products as antimicrobial agents. Clin. Microbiol. Rev. 1999, 
$12,564-582$.

41. EPW Kets. Natural antimicrobials for food preservation. Handbook of Food Preservation. 1999, 285-308.

42. Mau, J.L. ; Chen, C.P.; Hsieh, P.C. Antimicrobial effect of extracts from Chinese chive, cinnamon, and corni fructus. J. Agr. Food. Chem. 2001, 49, 183-188.

43. Russo, T.A.; Johnson, J.R. Proposal for a New Inclusive Designation for Extraintestinal Pathogenic Isolates of Escherichia coli: ExPEC. J. Infect. Dis. 2000, $181,1753-1754$.

44. Helander, L.M.; Alakomi, H.L.; Latva-Kala, K. Characterization of the action of selected essential oil components on Gram-negative bacteria. J. Agr. Food. Chem. 1998, 46, 3590-3595.

45. Stammati, A.; Bonsi, P.; Zucco, F.; Moezelaar, R.; Alakomi, H.L.; von Wright, A. Toxicity of selected plant volatiles in microbial and mammalian short-term assays. Food. Chem. Toxicol. 1999, 37, 813-823.

46. Cherrington, C.A.; Hinton, M.; Mead, G.C.; Chopra, I. Organic acids: Chemistry, antibacterial activity and practical applications. Adv. Microb. Physiol. 1991, 32, 87-108.

47. Ricke, S.C. Perspectives on the use of organic acids and short chain fatty acids as antimicrobials. Poultry. Sci. 2003, 82, 632-639.

48. P. Michael Davidson; T. Matthew Taylor. Chemical Preservatives and Natural Antimicrobial Compounds. 2007, Fundamentals and Frontiers, Chapter 33, 
doi:10.1128/9781555815912.ch33.

49. Booth, I.R. Regulation of cytoplasmic $\mathrm{pH}$ in bacteria. Microbiological Reviews. $1985,49,359-378$.

50. Hsiao, C.; Siebert, K.J. Modeling the inewhibitory effects of organic acids on bacteria. Int. J. Food. Microbiol. 1999, 47, 189-201. 